\title{
1,3-Dipolar cycloaddition of azomethine ylides generated from aziridines in supercritical carbon dioxide
}

\author{
Paulo J. S. Gomes, Cláudio M. Nunes, Alberto A. C. C. Pais, \\ Teresa M. V. D. Pinho e Melo* and Luis G. Arnaut \\ Department of Chemistry, Coimbra University, 3004-535 Coimbra, Portugal
}

Received 8 March 2006; revised 26 May 2006; accepted 30 May 2006

\begin{abstract}
The 1,3-dipolar cycloaddition of azomethine ylides with DMAD in supercritical carbon dioxide is reported. The photolysis reaction conditions were optimized with a suitable adjustment of pressure, temperature, irradiation time and co-solvent concentration leading to a more efficient reaction than in neat acetonitrile. Similar results were observed using thermal reaction conditions. Supercritical carbon dioxide with a minute co-solvent addition is shown to be a very efficient medium for promoting this type of cycloadditions.
\end{abstract}

(C) 2006 Elsevier Ltd. All rights reserved.

Over the last decade, supercritical fluids (SCF) received significant attention as a new class of environmentally friendly solvents for organic synthesis. Supercritical fluids have properties intermediate between the gas and the liquid phases that can be tuned simply by changing the pressure and temperature. In particular, changes of pressure close to the critical point enable drastic changes in density and viscosity. Supercritical carbon dioxide $\left(\mathrm{scCO}_{2}\right)$ has received special attention since it is readily accessible with low critical temperature $\left(T_{\mathrm{c}}=31^{\circ} \mathrm{C}\right)$ and moderate critical pressure $\left(P_{\mathrm{c}}=75.8\right.$ bar $)$. Supercritical carbon dioxide is also a desirable organic solvent replacement because it is abundant, inexpensive, nontoxic, non-flammable and easily separated from the reaction mixture. ${ }^{1}$

The study of model reactions is an efficient strategy to get knowledge on the chemical reactivity in $\mathrm{scCO}_{2}$. That is the case of the 1,3-dipolar cycloaddition, an important and general route to the construction of five-membered heterocyclic ring systems. ${ }^{2}$ However, 1,3-dipolar cycloaddition in $\mathrm{scCO}_{2}$ is an area almost unexplored and only reports on the cycloaddition of mesonitrile oxide and of 3-phenylsydnone are known. ${ }^{3}$ The cycloaddition of azomethine ylides is a particularly powerful method-

$\overline{\text { Keywords: }}$ Supercritical carbon dioxide; 1,3-Dipolar cycloaddition; Azomethine ylides; Aziridines.

* Corresponding author. Tel.: +351 239 854475; fax: +351 239

826068; e-mail: tmelo@ci.uc.pt ology for the synthesis of nitrogen-heterocyclic compounds. We chose the 1,3-dipolar cycloaddition of azomethine ylides generated from aziridines as the model reaction. Aziridines (1) undergo electrocyclic ring opening in a disrotatory manner upon irradiation and conrotatory ring opening upon thermolysis, giving azomethine ylides (2), which participate in 1,3-dipolar cycloadditions (Scheme 1).

As the first objective we decided to study the photolysis of aziridine $\mathbf{3}$ in the presence of dimethyl acetylenedicarboxylate (DMAD) using conventional reaction conditions (Scheme 2). Ethyl 3-phenylaziridine-2carboxylate 3 was prepared as described in the literature. ${ }^{4}$ We found that irradiation of a solution of $\mathbf{3}$ and DMAD in acetonitrile using a $\mathrm{Hg}$ lamp $\left(20^{\circ} \mathrm{C}\right.$, $\lambda=254 \mathrm{~nm}, 1 \mathrm{~h}$ ) affords 5-phenyl-2,3-dihydro-1 $H$-pyrrole-2,3,4-tricarboxylate $\mathbf{4}^{5}$ in $69 \%$ yield. Thus, the initially formed 1,3-dipolar cycloadduct isomerizes giving the final product. A $42 \mathrm{~min}$ irradiation in acetonitrile with the fourth harmonic $(266 \mathrm{~nm})$ of the Nd:YAG laser also gave 4 in $69 \%$ yield. Dicyano-sensitized photoreaction of aziridine 3 with DMAD was also carried out leading to compound 4 in $68 \%\left(20^{\circ} \mathrm{C}, \lambda=380 \mathrm{~nm}\right.$, $25 \mathrm{~min})$.

The optimization of the cycloaddition reaction in $\mathrm{scCO}_{2}$ requires the control of one additional variable, pressure, in addition to temperature and irradiation time. Cursory experiments revealed that the maximum efficiency 

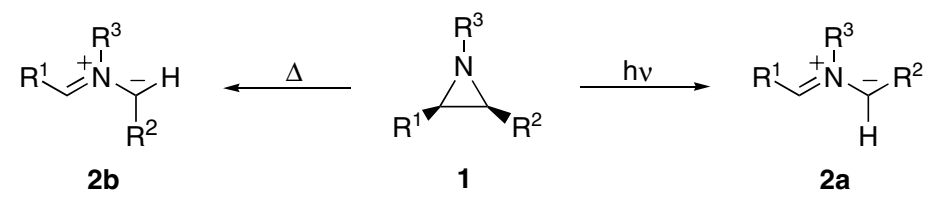

Scheme 1.<smiles>CCOC(=O)C1NC(c2ccccc2)=C(C(C)=O)C1C(C)=O</smiles>

$468 \%$

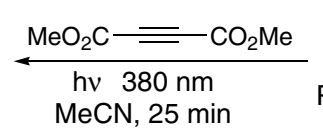

DCB

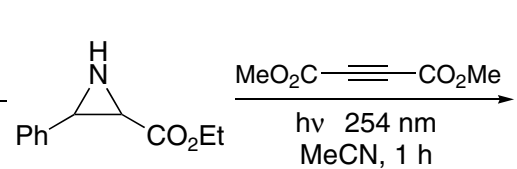

3<smiles>CCOC(=O)C1NC(c2ccccc2)=C(C(C)=O)C1C(C)=O</smiles>

$469 \%$

Scheme 2.

approached $43 \%$ at $110 \mathrm{bar}, 45^{\circ} \mathrm{C}$ and an irradiation time of $42 \mathrm{~min}$ with the fourth harmonic $(266 \mathrm{~nm})$ of the Nd:YAG laser. Clearly, the maximum yield in $\mathrm{scCO}_{2}$ is much less than in acetonitrile. Further improvement of the yield required the use of acetonitrile as co-solvent, which introduces a fourth variable in the optimization procedure. This optimization was conducted, as a first approach, resorting to a full $2^{k}$ factorial planning, with $k=4$ factors. These comprise pressure $(P)$, temperature $(T)$, irradiation time $\left(I_{t}\right)$ and the volume of acetonitrile $(V)$ as co-solvent. The initial objective function has the form

$$
\begin{aligned}
\text { yield }(\%)= & \text { cte }+a_{I_{t}} I_{t}+a_{V} V+a_{T} T+a_{P} P \\
& +a_{I_{t} V} I_{t} V+\cdots+a_{I_{t} V T} I_{t} V T+\cdots \\
& +a_{I_{t} V T P} I_{t} V T P
\end{aligned}
$$

A summary of factor levels and yields can be found in Table 1, while Table 2 summarizes the values of coefficients determined using a standard approach ${ }^{7,8}$ in which a normalization to -1 and +1 of the lower and upper level values was performed. Results in Table 2 suggest a discrimination of effects based on the interaction terms. In fact, all power 1 coefficients are negative, but interaction terms vary signal. Also, a significant number of interaction terms are, for the ranges used, of the same order of magnitude as the direct effect of each factor. One of the most substantial terms reveals a strong interaction between pressure and temperature. Consequently, pressure and temperature were transformed into density, and this variable was taken as the most significant one to characterize $\mathrm{scCO}_{2}$. The original 16 experiments were then transformed in a corresponding $2^{3}$ full factorial planning, without conducting further experiments. The results indicate that the reaction yield is higher for low density values of the reactant mixture. This allows the use of an additionally simplified form of Eq. 1, which includes only the irradiation time and the volume of added acetonitrile. Again, for normalized values of the levels, we obtain Eq. 2 that can be used to maximize yield. This function is represented in Figure 1 imposing a yield of $100 \%$. It possesses a singularity for $\sim 15$ min irradiation time; also, on the right branch, the zone $I_{t}<34$ min corresponds to unphysical negative
Table 1. The four factors in the $2^{4}$ factorial design and the respective yield

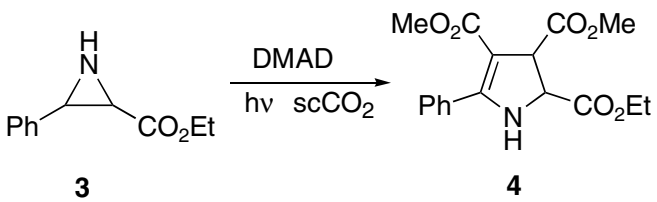

\begin{tabular}{lllll}
\hline$I_{t} / \mathrm{min}$ & $V / \mathrm{mL}^{\mathrm{a}}$ & $T /{ }^{\circ} \mathrm{C}$ & $P /$ bar & Yield $/ \%^{6}$ \\
\hline 20 & 0.1 & 35 & 110 & 42 \\
20 & 0.1 & 45 & 110 & 63 \\
40 & 0.1 & 35 & 140 & 43 \\
20 & 0.2 & 45 & 110 & 54 \\
20 & 0.2 & 35 & 110 & 31 \\
20 & 0.1 & 35 & 140 & 35 \\
40 & 0.2 & 35 & 140 & 21 \\
40 & 0.1 & 45 & 110 & 21 \\
40 & 0.2 & 45 & 140 & 27 \\
20 & 0.1 & 45 & 140 & 18 \\
40 & 0.2 & 35 & 110 & 28 \\
40 & 0.2 & 45 & 110 & 34 \\
20 & 0.2 & 35 & 140 & 44 \\
20 & 0.2 & 45 & 140 & 28 \\
40 & 0.1 & 45 & 140 & 27 \\
40 & 0.1 & 35 & 110 & 32 \\
\hline
\end{tabular}

${ }^{\text {a }}$ Volume of acetonitrile.

Table 2. Values of coefficients for a full $2^{4}$ factorial design (Eq. 1) $($ cte $=0.3425)$

\begin{tabular}{lllrll}
\hline$i$ & $a_{\mathrm{i}}$ & $i j$ & \multicolumn{1}{c}{$a_{i j}$} & $i j k$ & $a_{i j k}$ \\
\hline$I_{t}$ & -0.053 & $I_{t} \cdot V$ & -0.0071 & $I_{t} \cdot V \cdot T$ & 0.0223 \\
$V$ & -0.0096 & $V \cdot T$ & 0.0261 & $V \cdot T \cdot P$ & 0.003 \\
$T$ & -0.003 & $T \cdot P$ & -0.0511 & $I_{t} \cdot V \cdot P$ & 0.0446 \\
$P$ & -0.0385 & $I_{t} \cdot T$ & -0.0155 & $I_{t} \cdot T \cdot P$ & 0.0443 \\
& & $I_{t} \cdot P$ & 0.0422 & & \\
& & $V \cdot P$ & 0.0055 & & \\
\hline
\end{tabular}

volumes. A direct search for $I_{t}>34$ min lead to yields as high as $75 \%(t=42 \mathrm{~min}$ and $V=25 \mu \mathrm{L}$; Fig. 2). The accuracy of the model was tested conducting experiments in conditions anticipated to be less than ideal, and in all cases the yield was less than for the combination of parameters recommended by the model. The actual search along the set of variables anticipated to 


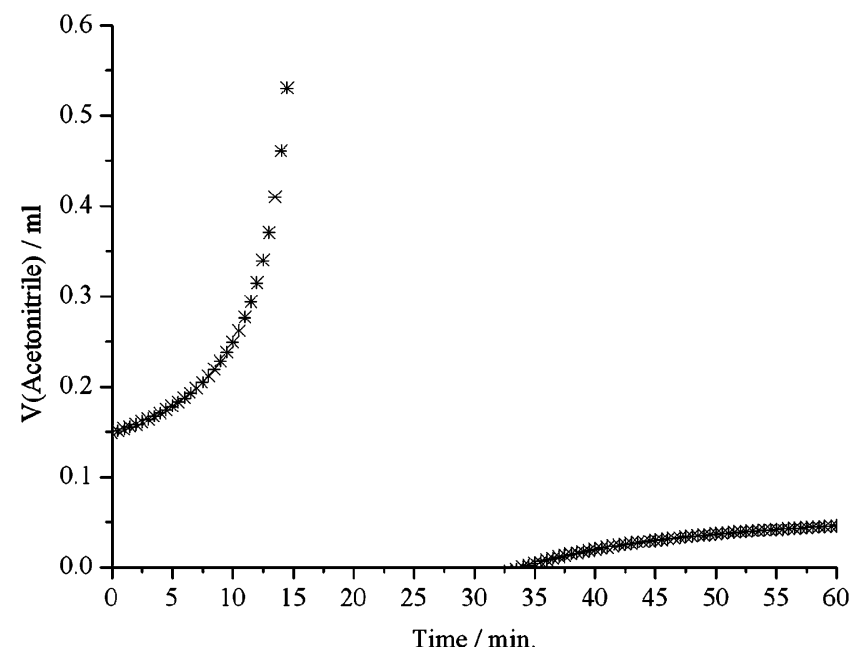

Figure 1.

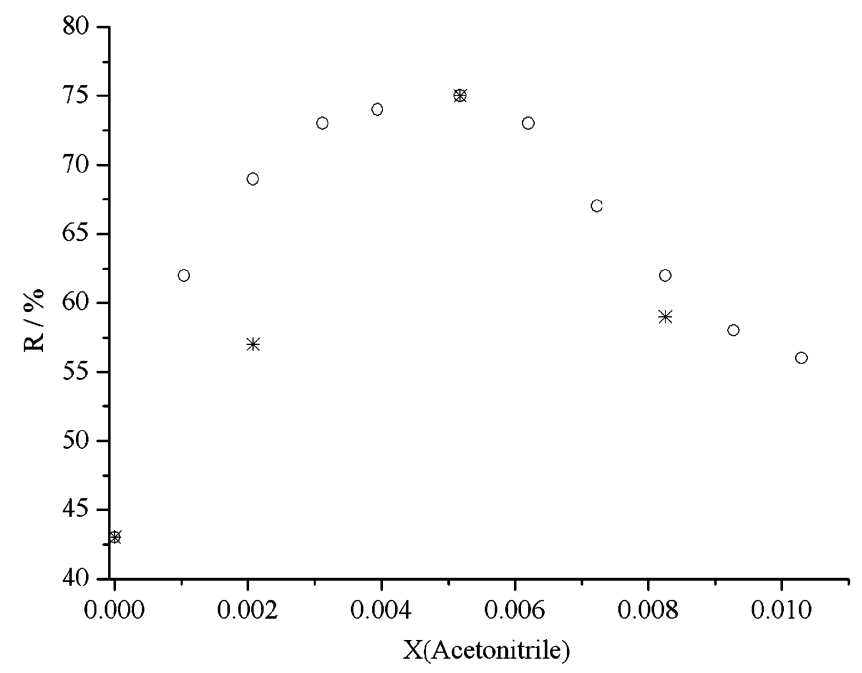

Figure 2.

give the highest yields is shown in Figure 2, together with two points representing experimental conditions that do not meet the model optimization for the smaller fraction of acetonitrile employed.

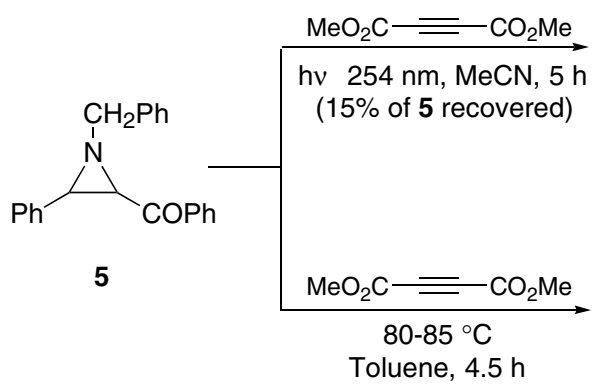

yield $(\%)=0.6511+0.0002 I_{t}+0.0157 \mathrm{~V}-0.0345 I_{t} V$

The model leads to the unexpected prediction that the maximum yield of the cycloaddition should be observed at low $\mathrm{scCO}_{2}$ densities and minute co-solvent concentrations. This was entirely verified experimentally. In particular, the yield is maximized when $23 \mathrm{~mol}$ of acetonitrile are present for $1 \mathrm{~mol}$ of aziridine and 2.3 mol of DMAD. ${ }^{9}$ This shows that only a thin solvatation layer is required to maximize the yield, and additional acetonitrile molecules are not necessary.

The work was extended to the study of the reactivity of aziridine $\mathbf{5}^{10}$ towards photolysis and thermolysis, in the presence of DMAD (Scheme 3). The irradiation of aziridine $\mathbf{5}$ in acetonitrile using a $\mathrm{Hg}$ lamp $\left(20^{\circ} \mathrm{C}\right.$, $\lambda=254 \mathrm{~nm}, 5 \mathrm{~h})$ gave pyrrole $6(38 \%)$ and pyrrole 7 $(19 \%)$, together with unreacted aziridine $5(15 \%)$. On the other hand, the cycloaddition of azomethine ylide generated by the thermolysis of aziridine 5 with DMAD produced pyrrole 6 in $42 \%$ yield as the only product.

The irradiation with the fourth harmonic $(266 \mathrm{~nm})$ of the Nd:YAG laser of aziridine $\mathbf{5}$ in the presence of DMAD in $\mathrm{scCO}_{2}$ led to pyrrole 6 in poor yield (3-5\%) and no improvement was observed using acetonitrile as co-solvent (Table 3). It is known that 2-benzoylaziridines can undergo a variety of photoinduced transformations namely intramolecular hydrogen atom, $\mathrm{C}-\mathrm{N}$ bond cleavage and $\mathrm{C}-\mathrm{C}$ bond cleavage. ${ }^{11}$ The main reaction pathway is determined by the photolysis reaction conditions. This observation is in agreement with our results, where different outcomes were observed when the irradiation was carried out with a Hg lamp and when the laser irradiation was employed.

The impossibility of achieving an efficient generation of the azomethine ylide from aziridine 5 using our photolysis conditions led us to study the thermal electrocyclic ring opening in the presence of DMAD in $\mathrm{scCO}_{2}$ (Table 4).

The thermolysis of aziridine $\mathbf{5}$ using conventional reaction conditions has shown that the $\mathrm{C}-\mathrm{C}$ bond cleavage is attainable at $80-85^{\circ} \mathrm{C}$ (see Scheme 3). Therefore, the thermolysis in $\mathrm{scCO}_{2}$ was carried out at $80{ }^{\circ} \mathrm{C}$,

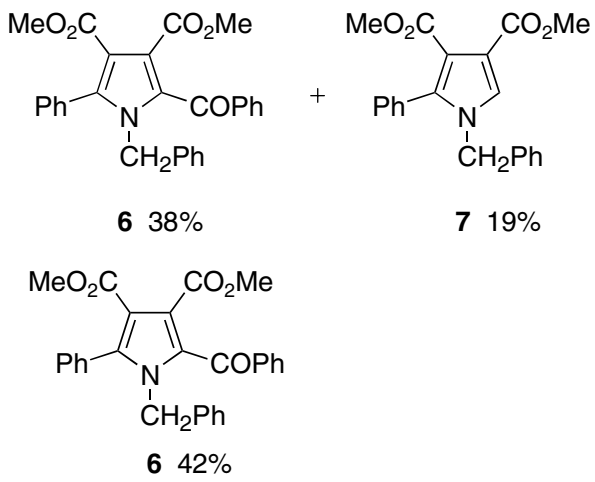


Table 3. Photolysis of aziridine 5 in the presence of DMAD in $\mathrm{scCO}_{2}{ }^{6}$<smiles>COC(=O)c1c(C(=O)OCc2ccccc2)c(C(=O)[O-])c(-c2ccccc2)n1Cc1ccccc1</smiles>

6

\begin{tabular}{lllll}
\hline$t / \mathrm{min}$ & $X^{\mathrm{a}}$ & $T /{ }^{\circ} \mathrm{C}$ & $P /$ bar & Yield $/ \%{ }^{6}$ \\
\hline 300 & - & 45 & 110 & 5 \\
150 & - & 45 & 110 & 3 \\
20 & 0.005 & 45 & 110 & 0 \\
\hline
\end{tabular}

${ }^{\mathrm{a}}$ Of acetonitrile.

Table 4. Thermolysis of aziridine 5 in the presence of DMAD in $\mathrm{scCO}_{2}{ }^{6}$

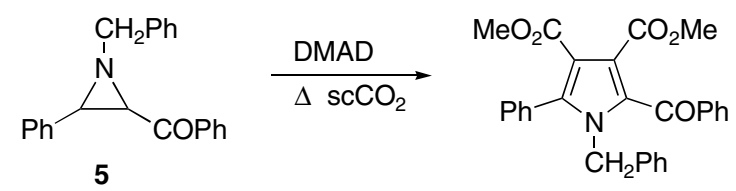

6

\begin{tabular}{lllll}
\hline$t / \mathrm{min}$ & $X^{\mathrm{a}}$ & $T /{ }^{\circ} \mathrm{C}$ & $P /$ bar & Yield $/ \%{ }^{6}$ \\
\hline 240 & - & 80 & 110 & 18 \\
240 & 0.005 & 80 & 110 & 53 \\
\hline
\end{tabular}

${ }^{\mathrm{a}}$ Of acetonitrile.

110 bar with a reaction time of $240 \mathrm{~min}$, which gave pyrrole 6 in $18 \%$ yield (Table 4 ). However, pyrrole 6 could be obtained in $53 \%$ yield when the reaction was carried out using acetonitrile as co-solvent $(X=0.005)$. Thus, a significant improvement was again achieved by performing the cycloaddition in $\mathrm{scCO}_{2}$ with a minute co-solvent addition.

The use of $\mathrm{scCO}_{2}$ with a minute addition of acetonitrile as co-solvent leads to cycloaddition yields higher than those obtained in neat solvents and that are achieved at lower reaction times. This demonstrates not only the environmental advantage of using $\mathrm{scCO}_{2}$ in organic synthesis, but also its cost-effectiveness in photochemical and thermal cycloadditions.

\section{Acknowledgements}

We thank Chymiotechnon and Fundação para a Ciência e a Tecnologia (POCI/QUI/55584/2004 and POCTI/ QUI/47267/2002) for financial support.

\section{References and notes}

1. (a) Brennecke, J. F.; Chateauneuf, J. E. Chem. Rev. 1999, 99, 433-452; (b) Tucker, S. C. Chem. Rev. 1999, 99, 391418; (c) Kajimoto, O. Chem. Rev. 1999, 99, 355-369; (d) Chattopadhyay, N.; Serpa, C.; Isilda Silva, M.; Arnaut, L. G.; Formosinho, S. J. Chem. Phys. Lett. 2001, 347, 361365; (e) Chattopadhyay, N.; Barroso, M.; Serpa, C.; Arnaut, L. G.; Formosinho, S. J. Chem. Phys. Lett. 2004, 387, 258-262; (f) Chattopadhyay, N.; Barroso, M.; Serpa,
C.; Isilda Silva, M.; Arnaut, L. G.; Formosinho, S. J. Chem. Phys. Lett. 2004, 387, 263-266.

2. (a) Gothelf, K. V.; Jørgensen, K. A. Chem. Rev. 1998, 98, 863-909; (b) Padwa, A. In Comprehensive Organic Synthesis; Trost, B. M., Fleming, L., Eds.; Pergamon: Oxford, UK, 1991; Vol. 4, p 1069; (c) Wade, P. A. In Comprehensive Organic Synthesis; Trost, B. M., Fleming, L., Eds.; Pergamon: Oxford, UK, 1991; Vol. 4, p 1111; (d) Coldham, I.; Hufton, R. Chem. Rev. 2005, 105, 27852809; (e) Nájera, C.; Sansano, J. M. Curr. Org. Chem. 2003, 7, 1105-1150; (f) Vedejs, E. In Advances in Cycloaddition; Curran, D. P., Ed.; JAI Press, 1988; Vol. 1, pp 33-51.

3. (a) Totoe, H.; McGowin, A. E.; Turnbull, K. J. Supercrit. Fluid 2000, 18, 131-140; (b) Lee, C. K. Y.; Holmes, A. B.; Al-Duri, B.; Leeke, G. A.; Santos, R. C. D.; Seville, J. P. K. Chem. Commun. 2004, 2622-2623.

4. Gelas-Mialhe, Y.; Touraud, E.; Vessiere, R. Can. J. Chem. 1982, 60, 2830-2851.

5. 2-Ethyl 3,4-dimethyl 5-phenyl-2,3-dihydro-1 $H$-pyrrole2,3,4-tricarboxylate 4 . The product was purified by flash chromatography [ethyl acetate-hexane (1:4) then ethyl acetate-hexane (1:3)] and was obtained as a white solid. $\mathrm{Mp} 103-105^{\circ} \mathrm{C}$ (from ethyl acetate-hexane). $v$ (KBr) $3065,3006,1748,1711,1703$ and $1629 \mathrm{~cm}^{-1}$; UV $\lambda_{\text {max }}=254 \mathrm{~nm} ; \quad \delta_{\mathrm{H}}\left(\mathrm{CDCl}_{3}, 300 \mathrm{MHz}\right) 0.95 \quad(3 \mathrm{H}, \mathrm{t}$, $J=7.1 \mathrm{~Hz}), 3.26(1 \mathrm{H}, \mathrm{d}, J=6.7 \mathrm{~Hz}), 3.65(1 \mathrm{H}, \mathrm{d}$, $J=6.7 \mathrm{~Hz}), 3.79(3 \mathrm{H}, \mathrm{s}), 3.88(3 \mathrm{H}, \mathrm{s}), 5.52(1 \mathrm{H}, \mathrm{s}, \mathrm{NH})$, $7.29-7.36(5 \mathrm{H}, \mathrm{m}, \mathrm{Ar}-\mathrm{H}) ; \delta_{\mathrm{C}}\left(\mathrm{CDCl}_{3}, 75.5 \mathrm{MHz}\right) 13.8$, $45.0,46.3,51.8,53.0,61.3,104.7,127.4,128.2,128.3$, 132.5, 155.6, 165.1, 165.7; MS (EI) $m / z 333\left(\mathrm{M}^{+}, 8 \%\right), 274$ (39), 260 (58), 228 (34), 200 (41), 131 (100), 103 (60) and 77 (48). Anal. Calcd for $\mathrm{C}_{17} \mathrm{H}_{19} \mathrm{NO}_{6}$ : C, 61.25; H, 5.75; N, 4.20. Found: C, 61.15; H, 5.43; N, 4.39.

6. The yields were determined by HPLC, with a column Hypersil BDS C18, kept at $40^{\circ} \mathrm{C}$, and a mixture of wateracetonitrile (50:50) as the mobile phase. In these conditions the retention times are as follows: aziridine 3, $1.83 \mathrm{~min}$; 2,3-dihydro- $1 H$-pyrrole 4, $4.80 \mathrm{~min}$; aziridine $\mathbf{5}$, $3.59 \mathrm{~min}$; pyrrole 6, $4.33 \mathrm{~min}$ and pyrrole 7, $2.89 \mathrm{~min}$. In all the experiments, a calibration curve was made, to obtain the concentration of products.

7. Massart, D. L.; Vandeginste, B. G. M.; Deming, S. N.; Michotte, Y.; Kaufman, L. Chemometrics: a Textbook; Elsevier, 1998.

8. Peixoto, A. F.; Pereira, M. M.; Pais, A. A. C. C., submitted for publication.

9. General procedures for the cycloaddition in supercritical carbon dioxide. $\mathrm{CO}_{2}$ (airliquide, N48) was passed through an Alltech charcoal trap and a Matheson Tri-Gas oxygen absorbing purifier (model 6410), before being allowed into the high-pressure reactor specifically built in our laboratory for these experiments. This reactor was made in stainless steel, with two sapphire windows $2.00 \mathrm{~cm}$ in diameter and $0.80 \mathrm{~cm}$ thick, sealed against the reactor body with indium wire partially embedded in circular cages drilled in the stainless steel. A magnetic stirrer placed inside the reactor kept the solutions homogenized during the irradiation process. Channels drilled in the reactor were connected to a Jasco thermostatic bath with external water circulation to maintain the reactor at the desired temperature. The high-pressure reactor has two external connections via $1 / 16^{\prime \prime}$ stainless steel tubes. One of them is connected, through a valve, to the high-pressure line, and the other to a digital pressure indicator (Omega DP20 and Schaevitz pressure sensor, precision $+0.25 \%$ ). In a typical experiment, $4.0 \mathrm{mg}$ of aziridine was introduced in our reactor together with $6 \mu \mathrm{L}$ of DMAD and the necessary amount of acetonitrile. The reactor was closed 
and connected to the high-pressure line. The reactor was flushed with $\mathrm{CO}_{2}$ to expel the air, and them it was pressurized with $\mathrm{CO}_{2}$. This procedure was made at low temperature to avoid evaporation or sublimation. The samples were irradiated with the fourth harmonic $(266 \mathrm{~nm})$ of a Spectra-Physics Quanta-Ray GCR-130 $\mathrm{Nd}$ :YAG laser.
10. Aziridine $\mathbf{5}$ was prepared as described in Southwick, P. L.; Christman, D. R. J. Am. Chem. Soc. 1952, 74, 18861891.

11. (a) Padwa, A.; Hamilton, L. J. Am. Chem. Soc. 1967, 89, 102-112; (b) Ramaiah, D.; Muneer, M.; Gopidas, K. R.; Das, P. K.; Rath, N. P.; George, M. V. J. Org. Chem. 1996, 61, 4240-4246. 